Łyszczarz B., Market concentration and performance of general hospitals in Poland, „Ekonomia i Prawo. Economics and Law.”, Polszakiewicz B., Boehlke J. (ed.), Vol. 13, No. 4/2014, pp. 499-510. DOI: http://dx.doi.org/10.12775/EiP.2014.035.

\title{
BŁAŻEJ ŁYSZCZARZ*
}

\section{MARKET CONCENTRATION AND PERFORMANCE OF GENERAL HOSPITALS IN POLAND}

\author{
SUMMARY
}

Theories of the hospital market view hospitals as competing for patients, physicians and third-party payers simultaneously. The competition involves such elements as price, quality, convenience, technology and innovation and the effects of the competition in the market affect the quality of care, clinical outcomes, cost of services, access as well as patient satisfaction.

The purpose of the paper is to shed some light on the impact of competition on the performance of general hospitals in Poland. Due to the unavailability of microlevel data, territorial concentration based on regional data is used as a proxy for the scope of competition. Therefore, the territorial concentration of hospital beds is measured with the use of the Herfindahl-Hirschman index (HHI) for each of the 16 provinces of Poland and for the four-year period of 2008-2011. In the second stage, the values of the concentration index are correlated with a set of variables describing the performance of hospitals.

The results show that the concentration of hospital beds in the regions is uneven. The regions with the most concentrated markets (zachodniopomorskie, łódzkie, podlaskie and mazowieckie) are characterized by four times higher values of the HHI than the one with the least concentrated market (ślackie). The results suggest that a higher concentration in the hospital market correlates with a larger number of patients treated and an increase in the cost of services.

Keywords: competition, hospitals, Herfindahl-Hirschman Index

JEL Classification: I11, D40, H51

* Błażej Łyszczarz, Nicolaus Copernicus University, Faculty of Health Sciences, Department of Public Health, ul. Sandomierska 16, 85-830 Bydgoszcz, phone: +48 525855409 , e-mail: blazej@cm.umk.pl. 


\section{INTRODUCTION}

Hospitals constitute a central subsector of health care systems in every developed country. In Poland there are around 800 general hospitals and hospital expenditures are the single-most important component of health spending, with a share of 35,4 percent of the total in 2010. The financing of hospitals absorbs 47 percent of the public payer's budget and amounts to around 2,3 percent of GDP. Not surprisingly, the performance of hospitals is exposed to vivid interest from all major stakeholders of the health care system. $\mathrm{Pa}$ tients, purchasers, employers, providers and policy-makers are all concerned with the functioning of the in-patient care in Poland. The concern is due to malfunctioning of the hospital services market. The availability of several procedures is low leading to long waiting times, while tight budget constraints together with inefficient management result in permanent debts and losses of numerous publicly and local authority owned providers.

One of the recent policies targeted to tackle hospital sector problems around the world is the increase of competition mechanisms in hospital markets. Competition-enhancing policies have been introduced or fostered in an increasing number of countries in last ten years. The United States, the United Kingdom and the Netherlands were among the first to strengthen competition mechanisms in the hospital industry and recently more of the OECD countries have followed their competition policies being motivated with rapid increases in health spending ${ }^{1}$.

The experience of Poland with competition in hospital services started in the late 1990s with an introduction of a purchaser-provider split ${ }^{2}$. Since then, all providers (including hospitals) that meet certain criteria have been allowed to compete for contracts signed with the National Health Fund (Narodowy Fundusz Zdrowia - NFZ) which is the main third-party payer in the system. Contracts in the in-patient care can be awarded by means of competitive tenders or negotiations. The principal rules for the competition mechanisms based on the separation of the purchaser and providers have not changed since their introduction and the competition between hospitals has

${ }^{1}$ OECD, Competition in Hospital Services, www.oecd.org/regreform/sectors/50527122.pdf, Paris 2012, p. 9 (18.06.2013).

2 The separation of the provider and purchaser in publicly funded health care systems enables competition to develop among providers and is seen as a mean to increase technical efficiency of providers (see T. Ashton, D. Press, Market concentration in secondary health services under a purchaser-provider split: the New Zealand experience, „Health Economics”, Vol. 6, No. 1/1997, p. 43). 
not led to positive results. The in-patient services market in Poland still lacks financial stability and patients' satisfaction from using hospital services is low. The reasons for the malfunctioning of the hospital sector, and generally health care, are subject to heated debate in Poland. Interestingly, the issue of competition is not present in the debate dominated by the problem of the funding level and in Polish literature, there are no empirical contributions concerned with the consequences of hospital competition.

The purpose of the empirical analysis conducted below is to shed some light on the impact of market concentration on the performance of the Polish hospital sector. To do so, a territorial concentration of hospital infrastructure is used as a proxy for market concentration. Both the theory of economics and extensive empirical evidence suggest that, other things being equal, the concentration of firms is an important element of the market structure and a determinant of competition ${ }^{3}$. The concentration is measured with the use of the Herfindahl-Hirschaman index and its values are correlated with indicators describing the performance of hospitals in the regions of Poland.

The succeeding parts of the paper address the following issues: overview of competition concept in health care; description of dataset and methods used; results; and conclusions.

\section{OVERVIEW OF COMPETITION CONCEPT AS APPLIED TO HOSPITAL SECTOR}

Under certain conditions, competition maximizes social welfare by bringing about an efficient provision of health care services with a socially optimal combination of price and quality ${ }^{4}$. Unfortunately, markets for hospital services differ extensively from the characteristics of a competitive market. The supply of hospital services is differentiated due to a highly heterogonous nature of the product and oligopolistic market structure. From the demand side, there are several issues regarding information asymmetry. Additionally, the presence of not-for-profit providers deviates the hospital sector from standard competitive market assumptions ${ }^{5}$. Moreover, there are legal, economic and social barriers for entering and exiting the market. The in-patient services mar-

${ }^{3}$ S.A. Rhoades, The Herfindahl-Hirschman Index, „Federal Reserve Bulletin”, Vol. 79, No. 3/1993, p. 188-189.

${ }^{4}$ L.C. Baker, Measuring Competition in Health Care Markets, „Health Services Research”, Vol. 36, No. 1/2001, Part II, p. 223.

5 OECD, op. cit., p. 29. 
ket is also characterized by very high transaction costs. As the basic competition assumptions are not fulfilled in the hospital sector, theory provides only limited guidance under what conditions and when competition leads to desirable outcomes.

The theories of the hospital market view hospitals as competing for patients, physicians and third-party payers simultaneously ${ }^{6}$. Competition involves such elements as price, quality, convenience, technology and innovation ${ }^{7}$. Numerous studies report the impact of competition on hospital performance, namely the quality of treatment, clinical outcomes, cost of services, access as well as patient satisfaction. The evidence on the impact of competition is ambiguous though, and a recent review of 53 studies concerned with competition in health care reports differentiated conclusions, e.g. that clinical outcomes are improved with increased competition in the United Kingdom, while the evidence from other countries suggest that these outcomes are reduced ${ }^{8}$. This vagueness probably reflect the fact that the success of competition often hinges on a regulatory and institutional settings adapted in a particular country as well as on responses from stakeholders of the system. Hence, a successful introduction of competition in health care often depends on the design of appropriate regulation ${ }^{9}$.

\section{DATA}

The availability of data on health care providers' activities in Poland is limited. Even information on the publicly owned entities is not published and the public statistics system covers only aggregated data. The level of aggregation varies for particular measures. For the purpose of the empirical analysis conducted here, the data used need to be disaggregated at least to the district (powiat) level. Using district-level data for each of the provinces (województwo) allows to identify the concentration of hospital activities in each of the provinces.

${ }^{6}$ I.C. Harris, R.R. McDaniel, Untangling healthcare competition, „Health Progress”, Vol. 74, No. 9/1993, p. 20-21.

7 P.A. Rivers, S.H. Glover, Health care competition, strategic mission, and patient satisfaction: Research model and propositions, "Journal of Health Organization and Management”, Vol. 22, No. 6/2008, p. 628.

8 The Health Foundation, Competition in healthcare, http://www.health.org.uk/publications/ competition-in-healthcare, p. 1 (18.06.2013).

${ }_{9}$ OECD, op. cit., p. 29. 
The most appropriate measures of hospital activity and the ones which are used frequently are the numbers of beds, discharger and patient days ${ }^{10}$. Due to the unavailability of other indicators, the measure used in this study is the number of beds in general hospitals in each of the districts of Poland.

The performance of hospitals is described with a set of following indicators: (1) number of patients treated per hospital bed; (2) number of patient days per capita; (3) average length of stay; (4) bed occupancy rate and (5) cost of services covered by the NFZ per 10.000 population expressed in constant prices.

The timespan of the analysis covers the period of 2008-2011. A multiperiod approach allows for investigating the dynamics of territorial concentration.

The data on the number of beds, hospital activities as well as cost of services is collected from various sources, namely: Local Data Bank ${ }^{11}$ (Bank Danych Lokalnych), annual reports of the National Health Fund ${ }^{12}$ (NFZ) as well as Ministry of Health Statistical Bulletin ${ }^{13}$.

\section{METHODS}

There are two stages of concentration analysis in this research. In the first stage, the territorial concentration of hospital beds in each of the 16 provinces (pl. województwo) of Poland is calculated using the Herfindahl-Hirschman index. The concentration index is based on district (pl. powiat) level data. In the second stage, the values of the HHI are correlated with various measures of hospital performance, to test for possible relationships between the concentration of providers and performance of the general hospitals sector.

The research uses the Herfindahl-Hirschman index (HHI), which is the most common measure of concentration used in empirical research. The HHI is a statistical measure that can be used to measure concentration in a variety of contexts, e.g. market or territorial concentration. The index accounts for the number of firms as well as their concentration, by incorporating the relative size of all firms in a market ${ }^{14}$.

${ }^{10}$ L.C. Baker, op. cit., p. 239.

${ }^{11}$ GUS, Local Data Bank, http://www.stat.gov.p1/bdlen/app/strona.html?p_name=indeks (18.06.2013).

12 NFZ, Sprawozdanie z dziatalności Narodowego Funduszu Zdrowia za 2011 rok, Warszawa 2012 (and previous issues).

${ }_{13}$ CSIOZ, Biuletyn Statystyczny Ministerstwa Zdrowia, Warszawa 2012 (and previous issues).

${ }^{14}$ S.A. Rhoades, op. cit., p. 188. 
The HHI is calculated by summing the squares of percentage market shares held by all the firms in a market investigated, as follows:

$$
H H I=\sum_{i=1}^{n}\left(M S_{i}\right)^{2},
$$

where:

$n$ - number of firms in the market,

$M S_{i}$ - market share of the $i$-th firm.

In the above formula, $M S_{i}$ represents a firm's market share, but it can also stand for territorial concentration. The latter interpretation of the HHI is used in the empirical analysis here.

The Herfindahl-Hirschman index determines how uneven the distribution of hospital beds is, compared with a uniform distribution. The value of the HHI increases with the degree of territorial concentration reaching its upper level of 1 if all the hospital beds in a province are concentrated in one district. The minimum value of the index is $1 / n$, which means that hospital beds are distributed evenly across all the districts. Thus, a lower value of the $\mathrm{HHI}$ indicates a less territorially concentrated hospital market in the province investigated ${ }^{15}$.

\section{RESULTS}

The results of empirical analysis are reported in two stages. The first stage is concerned with the values of the HHI in the provinces of Poland in the years of 2008-2011. In the second stage, an attempt is made to identify the association between territorial concentration and performance of general hospitals.

\subsection{CONCENTRATION AS AN INDICATOR OF COMPETITION AMONG HOSPITALS IN POLAND}

The average value of the HHI for the regions of Poland diminished slightly for the four years investigated and varied from 0,1461 in 2008 to 0,1451 in 2011 (table 1).

The highest values of the $\mathrm{HHI}$ in each of the years was observed in zachodniopomorskie, łódzkie, podlaskie and mazowieckie provinces. Therefore, these provinces were the ones characterized by the greatest territorial concen-

15 C. Campos, The Geographical Concentration of Industries, http://www.ons.gov.uk/ons/re1/regional-trends/regional-economic-analysis/the-geographical-concentration-of-industries/art-geographical-concentration.html, p. 13 (18.06.2013). 
tration in the hospital sector. The values of the HHI in these provinces fluctuated around 0,2, while in the region with the 5th highest HHI (małopolskie) it was considerably lower and reached the level of 0,176 in 2009. The high values of the $\mathrm{HHI}$ in the four aforementioned regions reflect considerable concentration of hospital beds in their capitals. The cities of Eódź, Warsaw, Szczecin and Białystok are characterized by a 41-43 percent share of all hospital beds in the respective provinces. Such a distribution of hospital infrastructure might affect both the performance of the hospital sector as well as inequities in access to services.

Table 1. Values of the Herfindahl-Hirschman index for territorial concentration in the provinces of Poland

\begin{tabular}{|c|c|c|c|c|}
\hline \multirow{2}{*}{ PROVINCE } & \multicolumn{4}{|c|}{ VALUE OF THE HERFINDAHL-HIRSCHMAN INDEX } \\
\hline & 2008 & 2009 & 2010 & 2011 \\
\hline dolnośląskie & 0.1490 & 0.1444 & 0.1401 & 0.1320 \\
\hline kujawsko-pomorskie & 0.1468 & 0.1461 & 0.1462 & 0.1408 \\
\hline lubelskie & 0.1341 & 0.1360 & 0.1281 & 0.1298 \\
\hline lubuskie & 0.1203 & 0.1192 & 0.1196 & 0.1212 \\
\hline tódzkie & 0.1992 & 0.2078 & 0.2075 & 0.2064 \\
\hline małopolskie & 0.1725 & 0.1757 & 0.1715 & 0.1700 \\
\hline mazowieckie & 0.2083 & 0.2062 & 0.1984 & 0.1984 \\
\hline opolskie & 0.1490 & 0.1481 & 0.1526 & 0.1525 \\
\hline podkarpackie & 0.0779 & 0.0777 & 0.0781 & 0.0797 \\
\hline podlaskie & 0.2084 & 0.2020 & 0.2115 & 0.2020 \\
\hline pomorskie & 0.1478 & 0.1499 & 0.1513 & 0.1496 \\
\hline śląskie & 0.0515 & 0.0500 & 0.0502 & 0.0503 \\
\hline świętokrzyskie & 0.1171 & 0.1192 & 0.1288 & 0.1331 \\
\hline warmińsko-mazurskie & 0.0957 & 0.0967 & 0.0968 & 0.1083 \\
\hline wielkopolskie & 0.1477 & 0.1502 & 0.1495 & 0.1483 \\
\hline zachodniopomorskie & 0.2126 & 0.2045 & 0.1975 & 0.1992 \\
\hline Average value & 0.1461 & 0.1459 & 0.1455 & 0.1451 \\
\hline
\end{tabular}

Source: own calculations based on Central Statistical Office, the National Health Fund and Ministry of Health data.

The province with the lowest level of territorial concentration of hospital beds in each of the years was śląskie; the HHI for the region varied slightly above the level of 0,05 , which means that the concentration was four times 
lower than in the provinces with the greatest concentration level. The second and the third regions with the least concentrated general hospitals markets were podkarpackie and warmińsko-mazurskie, respectively. The low level of concentration in śląskie reflects the highly urbanized character of the province and the fact that there are numerous cities of relatively similar size there. Also, the concentration of hospital infrastructure in provincial capital is very low; only 13,6 percent of beds is located in the city of Katowice.

The analysis of the HHI dynamics does not reveal any clear trend in concentration. In most of the provinces the HHI increased in some of the years, while decreased in other periods. The exceptions are świętkorzyskie and warmińsko-mazurskie, where the HHI values increased in every investigated year, as well as dolnośląskie, where the opposite tendency was observed and concentration decreased in every consecutive year.

\subsection{CONCENTRATION AS A DETERMINANT OF HOSPITAL PERFORMANCE IN POLAND}

The dispersion of the $\mathrm{HHI}$ values indicates that territorial concentration of the hospital market is differentiated in the regions of Poland. An important issue is whether these differences in concentration affect the performance of the hospital market in the regions.

In order to investigate potential relationships between the measure of concentration and the performance of providers, a set of variables describing activities of hospitals is used. Basic descriptive statistics for each of the five indicators and for the year 2008 as well as 2011 are reported in table 2.

Table 2. Selected descriptive statistics of hospital performance measures in the provinces of Poland

\begin{tabular}{|l|c|c|c|c|}
\hline \multirow{2}{*}{ VARIABLE } & \multicolumn{2}{|c|}{2008} & \multicolumn{2}{c|}{2011} \\
\cline { 2 - 5 } & AVERAGE & $\begin{array}{l}\text { STANDARD } \\
\text { DEVIATION }\end{array}$ & AVERAGE & $\begin{array}{l}\text { STANDARD } \\
\text { DEVIATION }\end{array}$ \\
\hline $\begin{array}{l}\text { Number of patients treated (patients/hospital bed/ } \\
\text { year) }\end{array}$ & 43.8 & 3.1 & 43.5 & 3.3 \\
\hline $\begin{array}{l}\text { Number of patient days per capita (days/capita/ } \\
\text { year) }\end{array}$ & 1.21 & 0.14 & 1.14 & 0.12 \\
\hline Average length of stay (days) & 5.86 & 0.51 & 5.56 & 0.43 \\
\hline Bed occupancy rate (per cent) & 70.2 & 3.4 & 66.5 & 2.7 \\
\hline $\begin{array}{l}\text { Real cost of services per 10.000 pop.* (thousands } \\
\text { of złoties) }\end{array}$ & 5379 & 406 & 6967 & 462 \\
\hline
\end{tabular}

* - for deflation purposes: $2010=100$.

Source: As in table 1. 
The dynamics of the indicators denote a decreasing intensity of hospital activities in the four-year period under investigation. Both the average number of patients treated per hospital bed as well as the mean quantity of patient days per capita diminished over the period. Similarly, the average length of stay in hospital decreased and the consequence of these trends is a lower bed occupancy rate. The only indicator the value of which increased during the period was the real cost of services paid by the NFZ. The increase was quite substantial, the real expenditure for hospital services in 2011 increased by 29,5 percent comparing to 2008 .

The relationships between the HHI values and the hospital performance measures were examined with the use of a simple correlation. The values of Pearson correlation coefficient are reported in table 3.

Table 3. Values of correlation coefficient between the Herfindahl-Hirschman index and the hospital performance measures

\begin{tabular}{|c|c|c|c|c|c|}
\hline & PATIENT__REAT & PATIENT_DAYS & LENGTH_STAY & BED_OCCUP & COST_SERVICES \\
\hline \multicolumn{6}{|c|}{2008} \\
\hline$H H I$ & 0.145 & -0.067 & -0.163 & -0.023 & 0.325 \\
\hline \multicolumn{7}{|c|}{2009} \\
\hline$H H I$ & 0.356 & 0.016 & -0.285 & 0.233 & $0.552^{* \star}$ \\
\hline \multicolumn{7}{|c|}{2010} \\
\hline$H H I$
\end{tabular}

For description of variables used see table 2 .

**, * - coefficient significant at 5 and 10 probability levels, respectively.

Source: As in table 1.

The values of the correlation coefficient show that in some of the cases significant relationships between territorial concentration and the measures of hospital performance were observed. Interestingly, the correlations for the year 2008 are considerably weaker from those observed in later periods. For the three recent years the relationships are more unambiguous in most of the cases. The discussion of the results below refers to the data from period 20092011.

There is a positive and quite strong correlation between the HHI and two variables, namely, the number of patients treated per hospital bed and cost of services. The positive sign of the relationship between territorial con- 
centration and cost of services is reasonable. If the definition of the HHI applied here reflects competition in hospital services correctly, than, one might expect a higher average cost of services paid by the NFZ in the regions with a higher values of the index. This can be explained by a higher monopolistic power of hospitals operating in regions with more concentrated markets. On the other hand, a positive association between the number of $\mathrm{pa}^{-}$ tients treated and the HHI is counterintuitive. It denotes that the number of patients treated per bed yearly increases with a higher market concentration. In other words, lower competition is associated with more efficient usage of hospital beds.

The relationship between the HHI and average length of stay is negative and it means that lower competition is associated with shorter stays in hospitals. It is not clear how to interpret this result in terms of efficiency. A shorter stay in hospital might be both efficiency-enhancing (if duration of stays tend to be too long and generate unnecessary costs) and efficiency-deteriorating (if stays tend to be too short and endanger patients' health status). This relationship is not statistically significant, though, and needs to be interpreted with caution.

Lower values of the correlation coefficient characterize the relationship between the HHI and two other variables, i.e. patient days and bed occupancy rate. Particularly, in the case of the first of these, the relationship is extremely weak.

\section{CONCLUSIONS}

The above analysis proved that the distribution of hospital beds is uneven. Hence, the concentration of in-patient services is diversified across the provinces of Poland. Whether the territorial concentration can be used as a proxy of competition is not undisputable. Unfortunately, the unavailability of micro-level data makes it impossible to conduct the analysis with more accurate information.

Agreeing with the use of territorial concentration as a proxy of competition, one might draw some conclusions on the competition impact on the performance of hospitals. Particularly, it was shown that lower competition is associated with higher average costs of services provided and a higher number of patients treated.

An introduction or a reinforcement of competition in the hospital market is not an obvious solution to enhance efficiency or to limit the growth of health care costs. In the recent literature, it is confirmed that for the com- 
petition forces to be effective, several conditions need to be $\operatorname{met}^{16}$. Firstly, a range of accessible options is a prerequisite for enabling patients to have choice in healthcare. Secondly, patients need to be interested and capable of choosing among services. What is more, relevant and understandable information need to be available to make well-informed choices. Finally, hospital staff must be responsive to financial incentives, which means that hospitals' revenues should be linked to a number of patients ${ }^{17}$. Hospital market competition arrangements in Poland do not meet all of the above conditions. Although the choice of provider is extensive, and patients are interested in choosing among services, one might conclude that information on the quality of services provided by particular hospitals is not sufficient to make rational choices. Moreover, there are doubts about the efficiency of financial incentives in the provider payment system, which lead to a situation in which hospitals are not interested in treating some cases, particularly those which are priced unprofitably by the purchaser.

\section{BIBLIOGRAPHY}

Ashton T., Press D., Market concentration in secondary health services under a purchaser-provider split: the New Zealand experience, "Health Economics”, Vol. 6, No. 1/1997, http://dx.doi.org/10.1002/(sici)1099-1050(199701)6:1\%3C43::aid-hec241\%3E3.0.co;2-i.

Baker L.C., Measuring Competition in Health Care Markets, „Health Services Research", Vol. 36, No. 1/2001, Part II.

Campos C., The Geographical Concentration of Industries, http://www.ons.gov.uk/ons/ rel/regional-trends/regional-economic-analysis/the-geographical-concentration-of-industries/art-geographical-concentration.html (18.06.2013).

CSIOZ, Biuletyn Statystyczny Ministerstwa Zdrowia, Warszawa 2012 (and previous issues).

GUS, Local Data Bank, http://www.stat.gov.pl/bdlen/app/strona.html?p_name=indeks (18.06.2013).

Harris I.C., McDaniel R.R., Untangling healthcare competition, „Health Progress”, Vol. 74, No. 9/1993.

NFZ, Sprawozdanie z dziatalności Narodowego Funduszu Zdrowia za 2011 rok, Warszawa 2012 (and previous issues).

OECD, Competition in Hospital Services, www.oecd.org/regreform/sectors/50527122. pdf, Paris 2012 (18.06.2013).

${ }_{16}$ OECD, op. cit., p. 11-12.

${ }^{17}$ Ibidem. 
Rhoades S.A., The Herfindabl-Hirschman Index, „Federal Reserve Bulletin”, Vol. 79, No. 3/1993.

Rivers P.A., Glover S.H., Health care competition, strategic mission, and patient satisfaction: Research model and propositions, ,Journal of Health Organization and Management", Vol. 22, No. 6/2008, http://dx.doi.org/10.1108/14777260810916597.

The Health Foundation, Competition in healthcare, http://www.health.org.uk/publications/competition-in-healthcare (18.06.2013). 